\title{
The Dendrothripinae(Thysanoptera, Thripidae) of Saudi Arabia, with new records, one new species, and revised status of Pseudodendrothrips stuardoi (Moulton)
}

\author{
IFTEKHAR RASOOL ${ }^{1,4}$, LAURENCE A. MOUND $^{2}$, AHMED M. SOLIMAN ${ }^{1,3}$ \& HATHAL M. ALDHAFER ${ }^{1,5}$ \\ ${ }^{1}$ Department of Plant Protection, College of Food and Agricultural Sciences, King Saud University, P.O. Box 2460, Riyadh 11451, KSA. \\ ${ }^{2}$ CSIRO Australian National Insect Collection, PO Box 1700, Canberra, ACT 2601. \\ झ"laurence.mound@csiro.au; $\odot$ https://orcid.org/0000-0002-6019-4762 \\ ${ }^{3}$ Zoology Department, Faculty of Science (Boys), Al-Azhar University, PO Box 11884, Nasr City, Cairo, Egypt \\ ="amsoliman@ksu.edu.sa; ammsoliman@gmail.com; @ https://orcid.org/0000-0001-5284-713X \\ 4”irasool@ksu.edu.sa; (1) https://orcid.org/0000-0002-8955-2340 \\ 5 ["hdhafer@ksu.edu.sa; @ https://orcid.org/0000-0002-4911-2332
}

\begin{abstract}
Two genera Dendrothrips Uzel and Pseudodendrothrips Schmutz are recorded from Saudi Arabia. A key is provided to eight members of Dendrothrips that have antennae with 9-segments and $D$. saudicus $\mathbf{s p .} \mathbf{n}$. is described in this group. $P$. aegyptiacus (Priesner) and P. stuardoi are newly reported from Saudi Arabia, with P. stuardoi rev. stat. from the leaves of Ficus carica being newly distinguished from P. mori (Niwa) that lives on the leaves of Morus alba. Some published records of $P$. mori from Mediterranean countries are possibly misidentifications of P. stuardoi.
\end{abstract}

Key words: Host plants, Morus alba, Ficus carica, Dendrothrips, Pseudodendrothrips

\section{Introduction}

The Dendrothripinae is smallest of the four subfamilies of Thripidae, comprising worldwide 106 species in 12 genera, and is found mainly in the tropics and subtropics (Alavi et al. 2014; ThripsWiki 2021). Six species in the genera Dendrothrips and Pseudodendrothrips have previously been recorded from the Arabian Peninsula, UAE and Yemen (zur Strassen \& van Harten 2006, 2008), but although Saudi Arabia is the largest part of the Peninsula, there is currently little knowledge of the Thysanoptera fauna of this country. Biogeographically, Saudi Arabia is a heterogeneous and interesting mixture of Afrotropical and Palaearctic elements with traces of the Oriental fauna, due to its position between Africa and Eurasia (Hölzel 1998; Abdel-Dayem et al. 2019). The objective here is to record the Thripidae subfamily Dendrothripinae from Saudi Arabia for the first time, with three species in the two genera Dendrothrips and Pseudodendrothrips. In addition to describing a new species of Dendrothrips, we record $P$. aegyptiacus as new to Saudi Arabia, and recall from synonymy P. stuardoi, indicating that this species lives on a different plant species from $P$. mori with which it has been confused.

\section{Material and methods}

This study involves specimens collected across central and southwestern regions of Saudi Arabia and comparisons with specimen of P. stuardoi from Chile and P. mori from Japan in the Australian National Insect Collection (ANIC). Specimens from Saudi Arabia are deposited in King Saud University Museum of Arthropods (KSMA), Riyadh, with a few in ANIC. All the measurements are in microns, and the terminology used follows Masumoto and Okajima (2017). 


\section{Genera of Dendrothripinae from Saudi Arabia}

1. Fore wing cilia arising ventrally behind anterior margin; wing apex without long setae (Figs 6, 7); hind tarsus at most one third

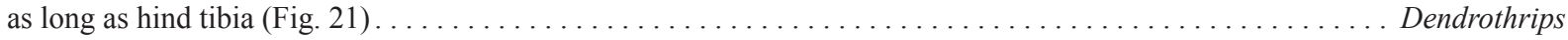
Fore wing cilia arising at anterior margin; wing apex with long setae (Fig. 18); hind tarsus more than half as long as hind tibia

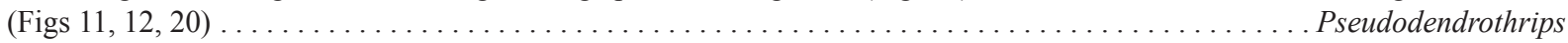

\section{Dendrothrips Uzel}

Dendrothrips Uzel, 1895: 159.

This is the largest genus of subfamily Dendrothripinae with 56 known species around the world (ThripsWiki 2021). From the Arabian Peninsula (Yemen) only D. cameroni and D. triumfettae have been recorded (zur Strassen \& van Harten 2006, 2008), and both were described from Africa. The genus Dendrothrips can be distinguished from other Dendrothripinae by the following character states: head with ocellar setae pair I absent; abdominal tergites median setal pair longer than distance between their bases; hind tarsus about one-third as long as hind tibia; fore wing apex rounded, without terminal seta (Mound \& Tree 2016).

\section{Dendrothrips species with 9-segmented antennae}

The presence of nine antennal segments among some species of Dendrothrips is considered to be a reversion from eight segments due to subdivision of the sixth segment (Zhang et al. 2019; Wang et al. 2019). In this genus 11 species are considered to share this condition, although the degree of separation between the segments varies from the partial or oblique division found in $D$. degeeri and D. julatteni, to the complete division in the new species described below. Four of the Dendrothrips species reported to have 9-segmented antennae are also reported to have the pronotum with a pair of prominent posteroangular setae: D. eastopi from Europe; D. oatleyi and D. oleae from South Africa; and D. saniishi from Khazakstan. (zur Strassen 1968). The remaining eight species, including D. saudicus sp. n. have all the pronotal posteromarginal setae equally small. These eight species may be distinguished as follows.

\section{Key to Dendrothrips species with 9-segmented antennae and no prominent pronotal setae}

(* indicates known only from description)

1. Sternites III-VI each with 8 to 12 setae along posterior margin [eastern Africa] $\ldots \ldots \ldots \ldots \ldots \ldots \ldots \ldots$. . . . . . . . . . . .

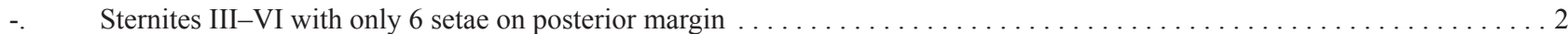

2. Body uniformly dark brown; fore wing uniformly shaded brown $[$ Europe, Iran $] \ldots \ldots \ldots \ldots \ldots \ldots$. . . . . . . degeeri

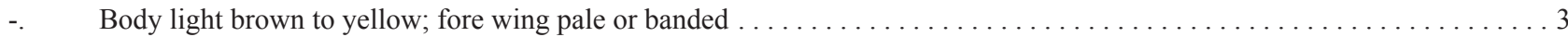

3. Antennal segments I-III uniformly dark brown in contrast to yellow segments IV-V and VI yellow on basal half; ocellar area with finely tuberculate sculpture $[$ Australia $] \ldots \ldots \ldots \ldots \ldots \ldots \ldots \ldots \ldots \ldots \ldots \ldots \ldots \ldots \ldots \ldots \ldots \ldots \ldots \ldots \ldots \ldots$ Antennal colour different; ocellar area with weak and irregular sculpture $\ldots \ldots \ldots \ldots \ldots \ldots \ldots \ldots \ldots \ldots \ldots \ldots$

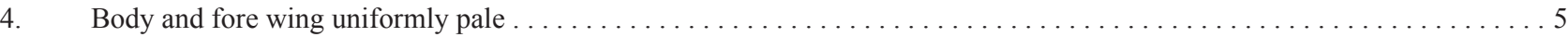

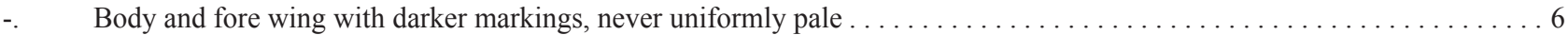

5. Fore wing first vein with 9-10, second 4-5 setae; head slender, $1.4-1.5$ times as wide as long [Canary Islands] . . . . . . .

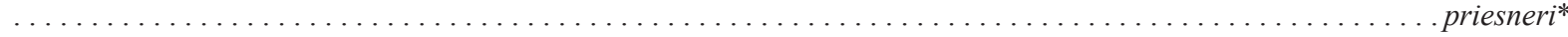
Fore wing first vein with $4-5$, second without setae; head transverse, $1.9-2.3$ times as wide as long . ........ kinape*

6. Head with paired group of three small setae anterolateral to ocellar area and close to compound eyes [South Africa] .......

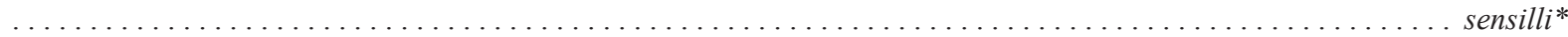
Head with only one pair of setae anterolateral to ocellar area $\ldots \ldots \ldots \ldots \ldots \ldots \ldots \ldots \ldots \ldots \ldots \ldots \ldots \ldots$

7. Head and antennal segment II as dark brown as metathoracic pleurites; fore wings uniformly light brown $[$ Australia] ......

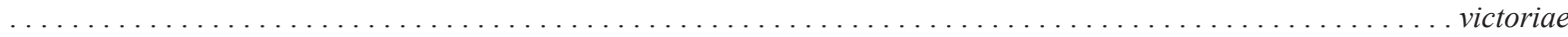
Head and antennal segment II pale, much paler than metathoracic pleurites; fore wings pale with two weakly shaded cross bands. . . . . . . . . . 


\section{Dendrothrips saudicus sp.n.}

Female macroptera: Body mainly yellow (Fig. 21), antennal segments I-II yellow, III-IV light brown, V-IX dark brown; pronotum, legs and pterothorax shaded brown irregularly, metapleura dark; abdominal segments III-VIII with lateral brown areas; fore wings pale with two transverse darker bands; clavus brown at apex.
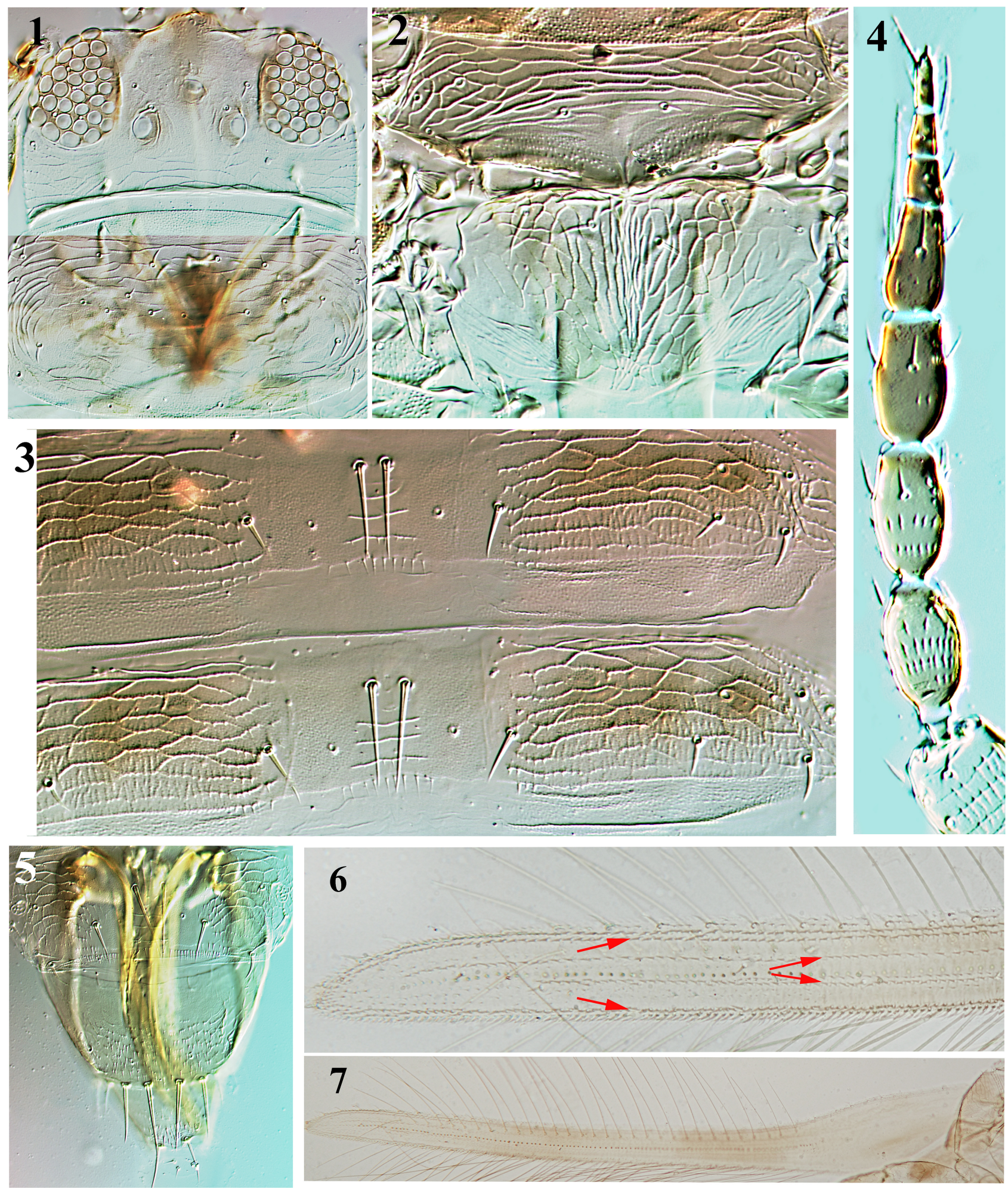

FIGURES 1-7. Dendrothrips saudicus sp. n.: (1) Head \& pronotum; (2) Metanotum; (3) Tergites V-VI; (4) Antennae; (5) Tergites VI-X; $(6,7)$ Fore wing (arrows indicate microtrichia on veins). 
Head with irregular weak sculpture lines on ocellar area with no internal markings; ocellar setae III no longer than diameter of an ocellus, arising in front of hind ocelli on lateral margin of triangle (Fig. 1); maxillary palps 2segmented. Antennae 9-segmented, III-IV with sense cone forked, VI with inner sense cone arising about on basal third of segment, extending to basal third of segment IX; microtrichia rows present on segments II-V and base of VI. Pronotum with irregular transverse reticulation, without internal markings; pronotal disc setae minute, posterior margin with 4-5 pairs of setae scarcely longer than discal setae, posteroangular setae no more than 15 microns long (Fig. 1). Mesonotum anterior half transversely reticulate, posterior half rugose without sculpture lines; metanotum longitudinally striate medially, irregular longitudinal reticulation laterally. Fore wings without microtrichia on interveinal membranes except rows of microtrichia at the veins, first vein with 8-9 minute setae, second vein with about 3 setae; clavus with one discal and 2 veinal setae, each no more than 5 microns long, also one terminal seta 15 microns long. Abdominal tergites III-VIII lateral thirds with transverse reticulations, posterior reticles on each tergite with weak longitudinal lines; posterior margin of tergites II-VII with 8-12 minute microtrichia medially; posterior margin of tergite VIII with complete comb of fine microtrichia, IX-X with microtrichia across posterior half of both segments (Fig. 5); pleurotergites sculptured without internal markings. Sternite with weak lines of sculptures laterally, IV-VII each with 3 pairs of small posteromarginal setae, without discal setae; anterior half of sternite VII with one pair of minute discal setae.

Measurements of holotype female in microns: Body length 1100. Head, length 100; width 185; ocellar setae III 8. Pronotum, length 95; width 215; posteroangular setae 13. Fore wing length 800. Metanotal median setae 10. Tergite IX major setae 40-50. Antennal segments I-IX length, $12 ; 35 ; 38 ; 35 ; 30 ; 25 ; 10 ; 10 ; 12$.

Material studied. Holotype female, SAUDI ARABIA, Al Baha, Baljurashi, Jarab-Baljurashi Rd., beaten from

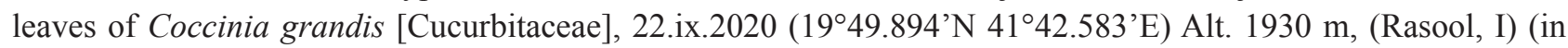
Senckenberg Museum, Frankfurt). Paratypes, two females collected with holotype (KSMA); Al Baha city, one female from leaves of Ficus carica [Moraceae], one female beaten from leaves of Pomegranate near Ficus carica, 23.ix.2020, (Rasool, I) (KSMA).

Comments. This new species is similar to the description of $D$. priesneri from the Canary Islands, but that was described as having the body and fore wings uniformly pale. In contrast, this new species has dark areas laterally on tergites III-VIII, the head, metanotum and legs have irregular light brown shadings, and the fore wing has two transverse shaded bands with the clavus brown at the apex. Moreover, the ocellar setae are only 5-8 microns long, whereas in priesneri the ocellar setae were described as 14-19 microns long.

\section{Pseudodendrothrips Schmutz}

Pseudodendrothrips Schmutz, 1913: 998.

There are 21 species listed in this genus (ThripsWiki 2021), mainly from the Asian tropics. Four of these are recorded from the Arabian Peninsula (zur Strassen \& van Harten 2006, 2008): P. aegyptiacus and P. ficus from Yemen, and P. ornatissimus and P. mori from UAE. We here record for the first time from Saudi Arabia the two species $P$. aegyptiacus and P. stuardoi. In this country the genus can be distinguished from other Dendrothripinae genera by the following character states: hind tarsi more than 0.5 as long as hind tibiae; antennae 8 or 9-segmented with forked sense cone on III-IV; abdominal tergites with median pair S1 setae close to each other and much longer than distance between their bases (Mound \& Tree 2016).

One species in this genus, P. mori, is associated with the leaves of Morus spp. (Masumoto \& Okajima 2017). This thrips was described from Japan but is also recorded from China and Korea (Kudo 1984), northern Italy (zur Strassen \& Marullo 2003), Iran (Alavi et al. 2014) and is well established on Morus alba in parts of north America (Stannard 1968). Moulton (1930) described a new genus and species from Chile, Graphidothrips stuardoi, on the leaves of Ficus carica. Subsequently, the genus Graphidothrips was synonymized with Pseudodendrothrips by Bhatti (1969), but the status of the species, stuardoi, remained unclear. It has been listed in ThripsWiki (2021) as a synonym of Pseudodendrothrips mori, although that synonymy was never formally published. The decision was based on an examination (by the present second author) of paratypes of stuardoi at the Natural History Museum, London, together with specimens at the Australian National Insect Collection, Canberra that were collected in Chile from the leaves of Ficus carica. 
The present studies have revealed character states that distinguish stuardoi from mori, and thus enable the identification of Pseudodendrothrips specimens on Ficus carica from Saudi Arabia. Moreover, descriptions and illustrations of $P$. mori in Stannard (1968) and Kudo (1984) conflict with the original description and specimens of $P$. stuardoi. The latter species has been found feeding and breeding across the central and Southwestern provinces of Saudi Arabia, but always on the leaves of $F$. carica. This tree is native to the Middle East and Mediterranean countries (Stover et al. 2007) and was introduced to South America around 1520 (Botti \& Muchnik 1998). Presumably the thrips was introduced with the plant material. This host association with Ficus carica contrasts with that of $P$. mori that is reported only from the leaves of Morus spp. (Stannard 1968; Kudo 1984; Alavi et al. 2014; Masumoto \& Okajima 2017).

The record of P. ficus from Yemen (zur Strassen \& van Harten 2006), based on two females, should probably be further checked. According to the original description (Hartwig 1948) this South African species has the hind tarsi 0.8 as long as the hind tibiae, as in P. stuardoi, but the mouth cone is illustrated as much shorter and the abdomen described as brown.

\section{Key to Pseudodendrothrips species from Saudi Arabia}

(P. mori included only for reference)

1. Antennae 8-segmented (Fig. 13); hind tibiae with two spines at apex (Fig. 12); body yellow with no dark markings .......

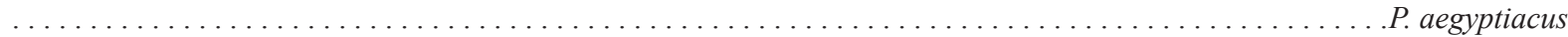
Antennae 9-segmented (Fig. 19); hind tibiae with one spine at apex (Figs 11, 20); body yellow with gray to light brown shad-

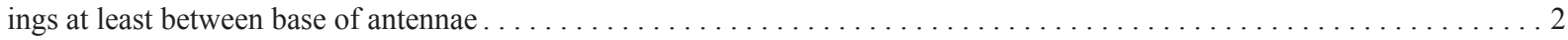

2. Mouth cone extending across mesosternum, maxillary palps 50 microns long (Fig. 16); hind tarsi at least 0.8 times as long hind tibiae (Fig. 20); fore wing first vein with 12-13 setae (Fig. 18); pronotal posteroangular setae S3 usually almost as long as S4

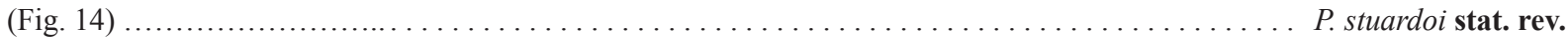
Mouth cone not extending beyond prosternum, maxillary palps less than 40 microns long; hind tarsi at most 0.6 times as long as hind tibiae (Fig. 11); fore wing first vein with about 6 setae; pronotal posteroangular setae S3 distinctly shorter than S4 (Fig.

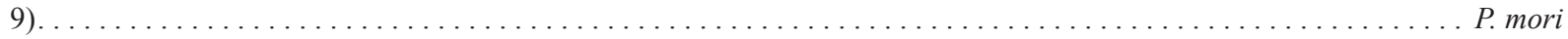

\section{Pseudodendrothrips aegyptiacus (Priesner)}

Phlebothrips aegyptiacus Priesner, 1965: 284.

This species was described from Egypt and is recorded from the Canary Islands and South Africa as well as Israel, UAE and Yemen. In Saudi Arabia, it has been found breeding on the leaves of Anisotes sp. although it has also been collected from leaves of Coccinia grandis. In common with the species $P$. kulshresthai, P. alexei, and P. maculosus this species has 8 -segmented antennae (Mound \& Tree 2007), although it differs from them in having the body unicolorous yellow and the hind tibiae with two spines at the apex (Fig. 12). Two females from Abu Dhabi have been studied and on one of these one antenna has segment VI entire but VII is subdivided, thus producing a 9-segmented condition of the antenna (see Zhang et al. 2019).

Material studied. SAUDI ARABIA, Al Baha, Baljurashi, Jarab-Baljurashi Rd. 4 females beaten from leaves of Coccinia grandis [Cucurbitaceae], 22.ix.2020; Al Makhwa, Shada Al aala, Qarwiya, 8 females and 5 larvae beaten from leaves of Anisotes sp. [Acanthaceae], 26.ix.2020, (Rasool, I), (KSMA).

\section{Pseudodendrothrips mori (Niwa)}

Belothrips mori Niwa, 1908: 180.

Described originally from Japan, with the holotype now unknown, this species has been re-described by Stannard (1968) and Kudo (1984). It is closely related to P. bhattii from which it can be distinguished by the pale body with head and fore wings pale (Alavi et al. 2014; Masumoto \& Okajima 2017). Moreover, the female of $P$. mori is also similar to the female of $P$. darci, a species from northern Australia and southeast Asia, although that is distinguished 
by the presence of a pair of stout pointed setae laterally on abdominal segment IX (Mound 1999). In addition to the character states indicated in the key above, it seems that $P$. mori and $P$. bhattii differ from many species of this genus (including aegyptiacus and stuardoi) in having ocellar setae pair I anterior to or anterolateral to the first ocellus, instead of clearly lateral or even completely absent. Currently P. mori is known from Iran but not from Saudi Arabia. The records of $P$. mori from Yemen, and also from UAE, require further checking as they are possibly misidentifications of $P$. stuardoi.

Material studied. JAPAN, Chiba Narita, female from leaf of Morus bombycis, 7.vi.2015 (M. Masumoto) in ANIC.

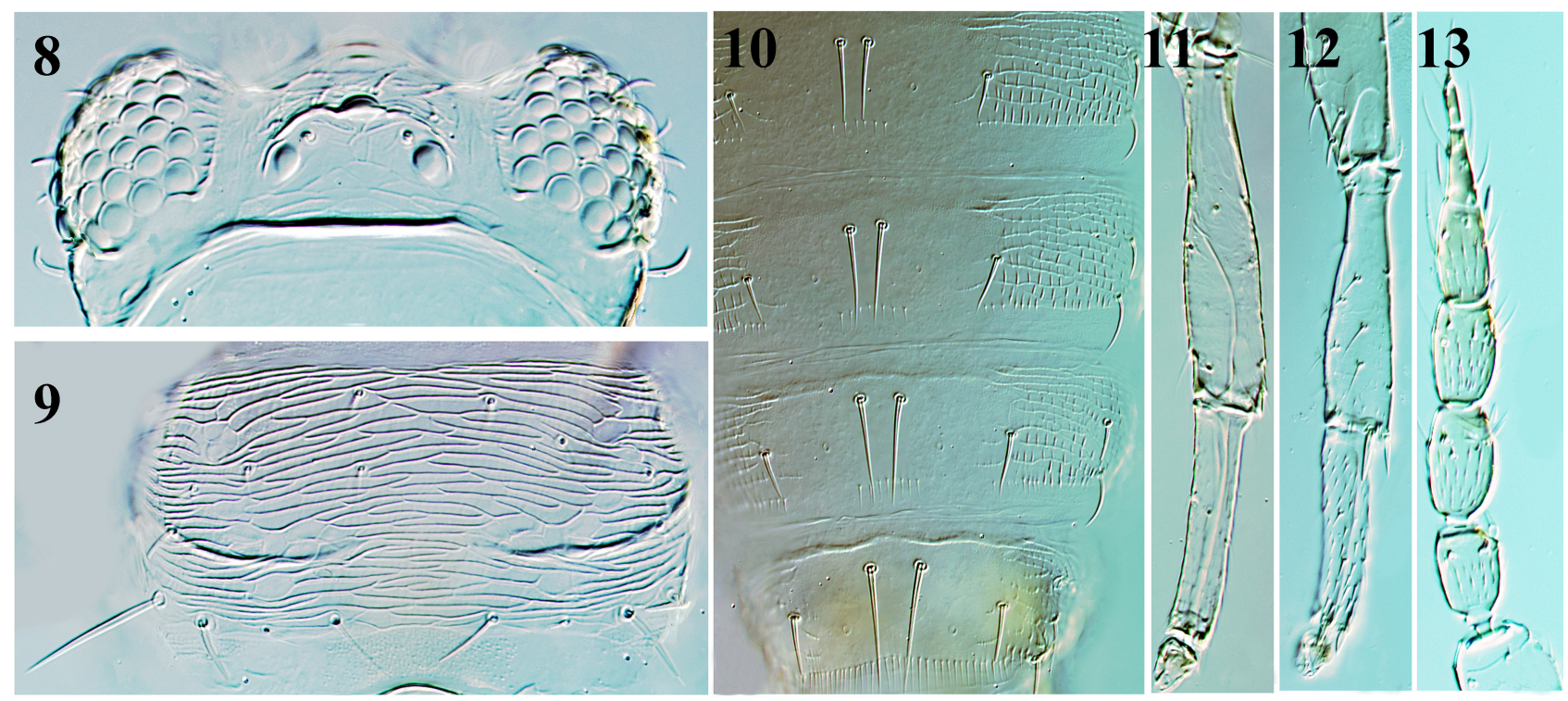

FIGURES 8-13. Pseudodendrothrips species. P. mori: (8) Head; (9) Pronotum; (10) Tergites V-VIII; (11) Hind tibia \& tarsus. P. aegyptiacus: (12) Hind tibia \& tarsus; (13) Antenna.

\section{Pseudodendrothrips stuardoi (Moulton) stat. rev.}

Graphidothrips stuardoi Moulton, 1930: 273

This species was described from Chile, where it was reported as damaging cultivated Ficus carica in the northern part of the country (Moulton 1930). As discussed above, it was presumably introduced to the New World together with its host plant, and the species is here distinguished from P. mori with which it had been synonymized. The most reliable diagnostic character states are the lengths of the maxillary palps and hind tarsi, these structures being considerably longer in the specimens of stuardoi than in the available specimens of mori. Moreover, the number of setae on the first vein is higher in females of stuardoi than in those of mori, although males have fewer of these setae. The inner pair of pronotal posteroangular setae (S3) are not constant in length in stuardoi but generally are considerably longer than in mori. The specimens identified as P. mori from UAE by zur Strassen \& van Harten (2008) are possibly stuardoi, based on the characters considered her, and records of $P$. mori from Turkey and Mediterranean countries also need further investigation.

Female macroptera (Fig. 23). Body pale yellow, head, pronotum and pterothorax pale yellow; abdominal tergites III-VII shaded gray to light brown laterally; antennal segment I pale, II brown, III-V gradually gray from base to tip, VI-IX light brown; clavus and fore wings clear with light brown cilia. Head without sculpture except few longitudinal lines at ocellar triangle; ocellar setae pair I arising lateral to fore ocelli, pair III arising within triangle in front of hind ocelli; compound eyes with about 7 stout setae and 18-20 pigmented facets; mouth cone long, slender, reaching to posterior margin of mesonotum; antennae 9-segmented, III \& IV with forked sense cone, VI with inner sense cone reaching to base of VII, VIII with outer sense cone exceeding the tip of IX. Pronotum with transverse striation with about 12 discal setae; posteroangular inner setae almost as long as outer setae. Metanotum with longitudinal striae at middle, reticulate laterally without internal markings. Fore wing first vein with 11-13 setae in a row, second vein without setae. Hind tibiae with one stout spine at apex; hind tarsi at least 0.8 times as long as, or in 
some individuals as long as, hind tibiae. Tergites II-VII with transverse striae laterally, provided with longitudinal small lines without internal markings; tergites III-VII with 4-10 minute microtrichia medially at posterior margin; VIII with complete comb of microtrichia; IX-X with rows of microtrichia at posterior half. Sternites without discal setae.

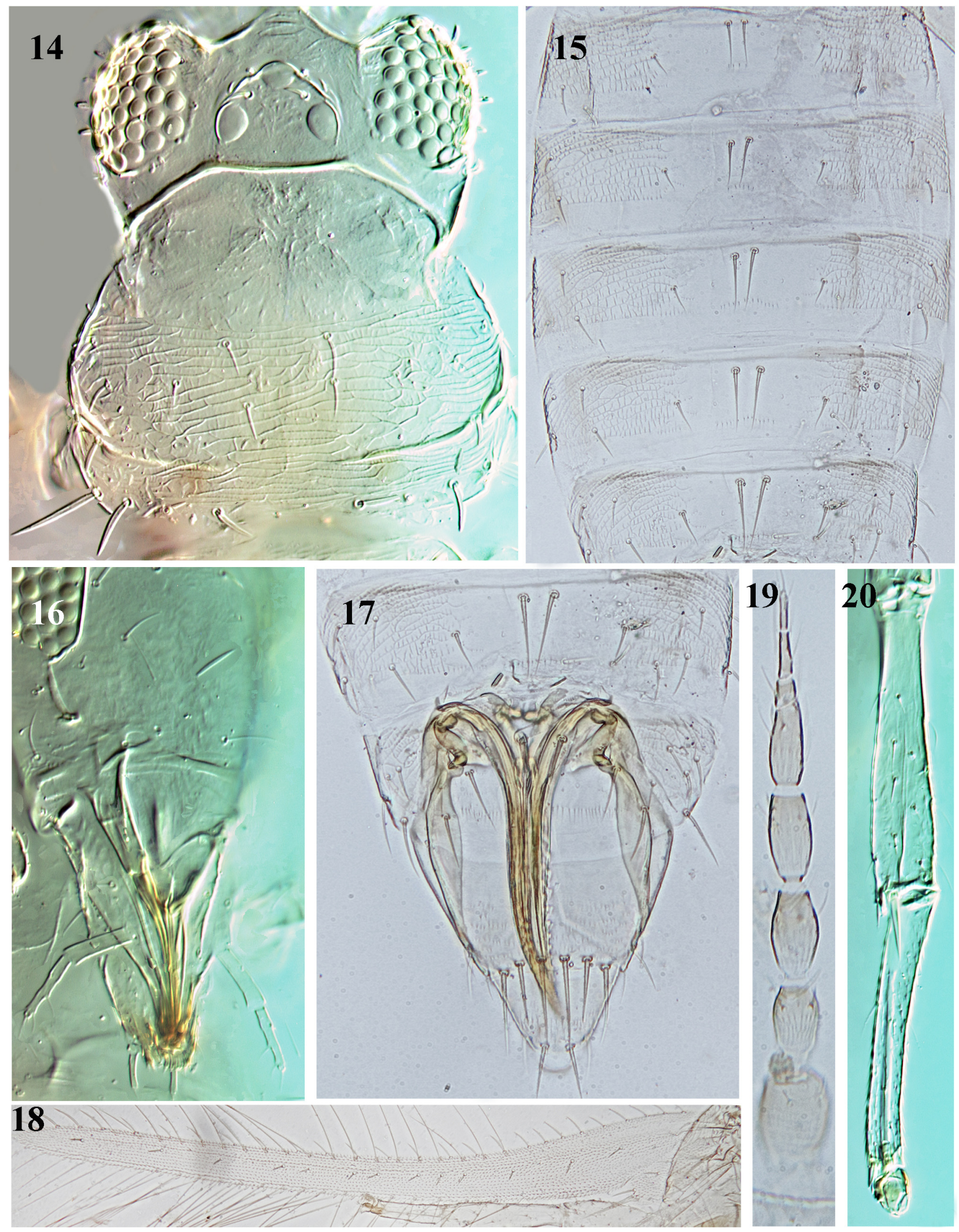

FIGURES 14-20. Pseudodendrothrips stuardoi: (14) Head \& pronotum; (15) Tergites III-VII; (16) Mouth cone \& maxillary palp; (17) Tergites VII-X; (18) Fore wing; (19) Antennae; (20) Hind tibia \& tarsus. 
Measurements. Body length 845. Head, length 55, width 155; ocellar setae pair III 10. Pronotum, length 75, width 175; posteroangular setae S1-S4 20, 10, 25, 25. Metanotum median setae 8. Fore wing length 585 . Antennal segments I-IX, 18, 30, 30, 32, 30, 30, 10, 20, 15.

Male macroptera (Fig. 24). Similar to female, but paler and smaller. Sternites without pore plates.

Measurements. Body length 670. Head, length 68, width 140; ocellar setae pair III 10. Pronotum, length 60, width 160; posteroangular setae S1-S4 15, 8, 20, 20. Metanotum median setae 8. Fore wing length 460. Antennal segments I-IX, 17, 30, 30, 35, 30, 30, 10, 17, 15.

Material studied. CHILE, San Felix, 2 paratype females, 16.i.1929 (Carlos Stuardo) in BMNH; San Vincente, Los Andes, 7 females, 1 male with larvae from Ficus carica, 10.iii.2003 (Renato Ripa) in ANIC. Saudi Arabia, Al Baha, Baljurashi, 11 females, one male, 10 larvae beaten from leaves of Ficus carica, 22.ix.2020; Al Baha, 5 females, 3 larvae from leaves of Ficus carica, 22.ix.2020; 27 females, 13 males, 45 larvae from leaves of Ficus carica, 23.ix.2020; Al Makhwa, 14 females, one male, two larvae from leaves of Ficus carica (Rasool, I); Riyadh, King Saudi University Educational farm, 9 females, 9 males, 32 larvae from leaves of Ficus carica, 23.vii.2020, (Rasool, I); same locality, 3 females, 3 males from grasses under Ficus carica, 13.vii.2020, (Soliman, A) in KSMA.

Comments. This species is readily distinguished from P. mori by the length of the mouth cone and maxillary palps, the larger number of setae on the fore wing first vein, the more elongate hind tarsi, and the presence of 18-20 pigmented facets on each compound eye (in contrast to 6 pigmented facets in mori).

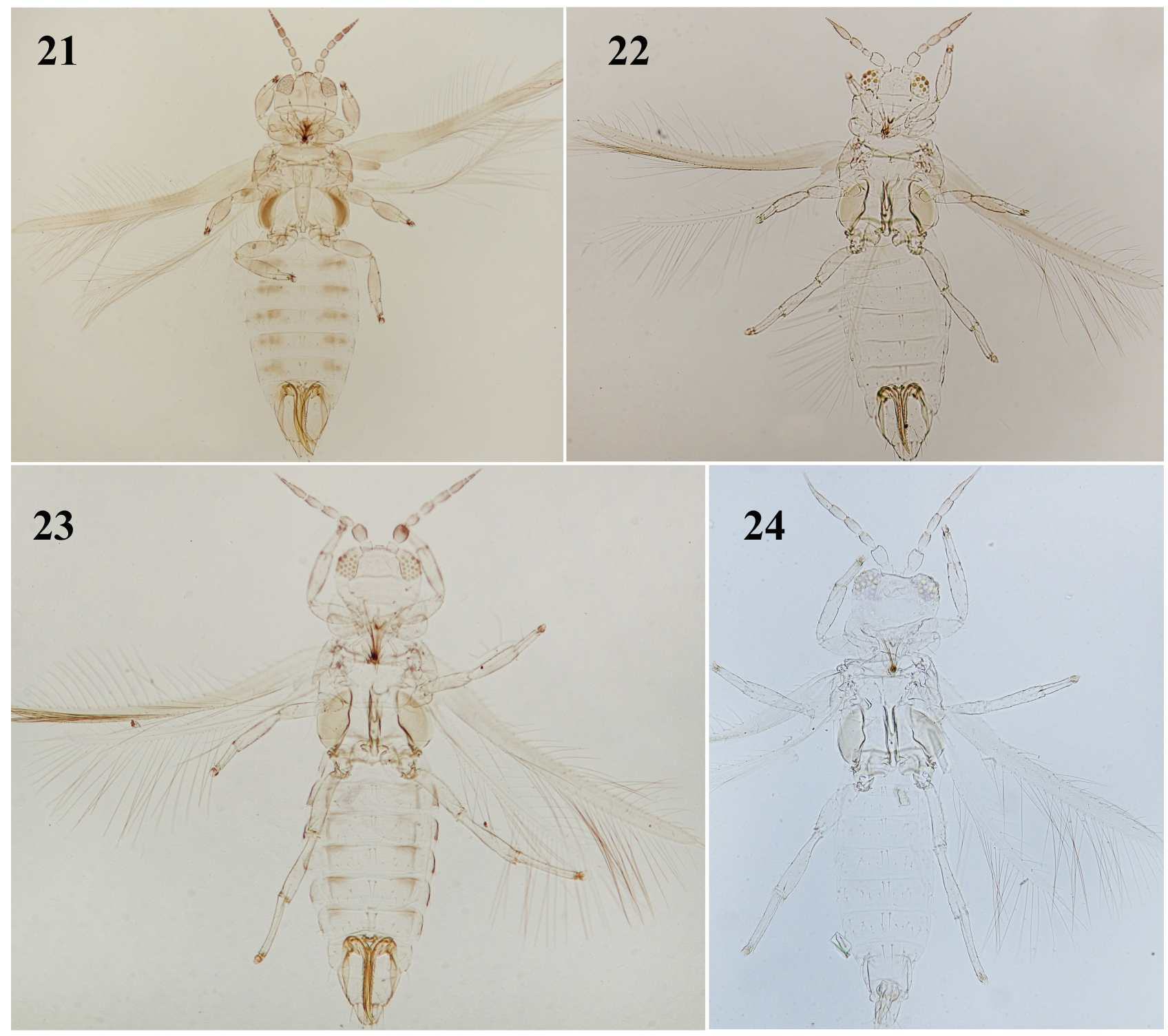

FIGURES 21-24. Dendrothripinae species: (21) Dendrothrips saudicus sp. n. (22) Pseudodendrothrips aegyptiacus. (23) P. stuardoi female. (24) P. stuardoi male. 


\section{Acknowledgements}

The authors thank the Deanship of Scientific Research at King Saud University for funding this work through research group No. RG-1437-009 and RSSU for their technical support. Laurence Mound is grateful to Renato Ripa in Chile and Masami Masumoto in Japan for providing specimens.

\section{References}

Abdel-Dayem, M.S., Elgharbawy, A.A., Rasool, I., Nagel, P. \& Aldhafer, H.M. (2019) The Carabidae (Coleoptera) of Shada Al-A'Ala Nature Reserve, Southwestern Saudi Arabia, with description of a new species of Paussinae. ZooKeys, 812, 93-131. https://doi.org/10.3897/zookeys.812.30937

Alavi, J.A., Minaei, K. \& Fekrat, L. (2014) The Iranian Dendrothripinae (Thysanoptera: Thripidae) with description of a new genus and species. Zootaxa, 3860 (5), 479-486. https://doi.org/10.11646/zootaxa.3860.5.6

Bhatti, J.S. (1969) Some synonyms chiefly among Indian Thysanoptera. Journal of the Bombay Natural History Society, 66, 64-69.

Botti, C. \& Muchnik, E. (1998) Fig production in Latin America. Acta Horticulturae, 480, 37-42. https://doi.org/10.17660/ActaHortic.1998.480.4

Hartwig, E.K. (1948) Six new species of South African Thysanoptera, with statistical analyses of measurements. Journal of the Entomological Society of Southern Africa, 11, 83-126.

Hölzel, H. (1998) Zoogeographical features of Neuroptera of the Arabian Peninsula. Acta Zoologica Fennica, 209, 129-140.

Kudo, I. (1984) The Japanese Dendrothripini with Descriptions of Four New Species (Thysanoptera, Thripidae). Kontyu, Tokyo, $52(4), 487-505$.

Masumoto, M. \& Okajima, S. (2017) Studies on Dendrothripinae (Thysanoptera, Thripidae) from Japan, with new records and one new species. Zootaxa, 4362 (3), 405-420. https://doi.org/10.11646/zootaxa.4362.3.5

Moulton, D. (1930) A new genus and species of Thysanoptera from Chile with notes on other species. Revista Chilena d'Historia naturales, 32, 272-275.

Mound, L.A. (1999) Saltatorial leaf-feeding Thysanoptera (Thripidae, Dendrothripinae) in Australia and New Caledonia, with newly recorded pests of ferns, figs and mulberries. Australian Journal of Entomology, 38 (4), 257-273. https://doi.org/10.1046/j.1440-6055.1999.00112.x

Mound, L.A. \& Tree, D.J. (2007) Oriental and pacific Thripidae (Thysanoptera) new to Australia with a new species new species of Pseudodendrothrips Schmutz. Australian entomologist, 34 (1), 7-14.

Mound, L.A. \& Tree, D.J. (2016) Genera of the leaf-feeding Dendrothripinae (Thysanoptera, Thripidae), with new species from Australia and Sulawesi, Indonesia. Zootaxa, 4109 (5), 569-582. https://doi.org/10.11646/zootaxa.4109.5.5

Niwa, S. (1908) Belothrips mori n.sp. on mulberry leaves [in Japanese]. Transactions of the Entomological Society of Japan, $2,180-181$

Priesner, H. (1965) A monograph of the Thysanoptera of the Egyptian deserts. Publications de la Institut Desert Egypte, 13, $1-549$.

Schmutz, K. (1913) Zur Kenntnis der Thysanopterenfauna von Ceylon. Sitzungsberichte der Kaiserlichen Akademie der Wissenschaften, 122 (7), 991-1089.

Stannard, L.J. (1968) The Thrips, or Thysanoptera, of Illinois. Bulletin of the Illinois Natural History Survey, 29, $213-552$. https://doi.org/10.21900/j.inhs.v29.166

Stover, E., Aradhya, M., Ferguson, L. \& Crisosto, C.H. (2007) The fig: overview of an ancient fruit. Horticultural Science, 42 (5), 1083-1087. https://doi.org/10.21273/HORTSCI.42.5.1083

ThripsWiki (2021) ThripsWiki - providing information on the World's thrips. Available from: http://thrips.info/wiki/Main_Page (accessed 20 February 2021)

Uzel, H. (1895) Monographie der Ordnung Thysanoptera. Königratz, Bohemia, 472 pp.

Wang, Z., Mound, L.A. \& Tong, X. (2019) Character state variation within Dendrothrips (Thysanoptera: Thripidae) with a revision of the species from China. Zootaxa, 4590 (2), 231-248. https://doi.org/10.11646/zootaxa.4590.2.2

Zhang, S.M., Mound, L.A. \& Feng, J.N. (2019) Systematic significance of antennal segmentation and sense cones in Thripidae (Thysanoptera: Terebrantia). Zootaxa, 4554 (1), 239-254. https://doi.org/10.11646/zootaxa.4554.1.8

zur Strassen, R. (1968) Tabellarische Arten-übersicht der Fransenflügler-Gattung Dendrothrips Uzel 1895 (Thysanoptera: Thripidae). Journal of the entomological Society of southern Africa, 31, 213-220.

zur Strassen, R. \& Marullo, R. (2003) Aggiornamenti all checklist delle specie della fauna italiana VIII Contributo. Bollettino della Societ Entomologica Italiana, 134, 191-194

zur Strassen, R \& van Harten, A. (2006) Record of thrips (Insecta: Thysanoptera) from Yemen, with comments on nocturnal flight activities. Fauna of Arabia, 21, 179-187.

zur Strassen, R. \& van Harten, A. (2008) Order Thysanoptera. Arthropod fauna of the UAE, 1, 133-152. 